Special issue of the 3rd International Conference on Computational and Experimental Science and Engineering (ICCESEN 2016)

\title{
Effects of Third-generation LED LCU on Nanomechanical Properties of Orthodontic Adhesives
}

\author{
F. Bilgic ${ }^{a, *}$, H. Altan ${ }^{b}$, Ö. Akinci Sözer ${ }^{a}$, Z. Arslanoglu ${ }^{c}$, E. Kale $^{d}$ And S. Özarslan \\ ${ }^{a}$ Mustafa Kemal University, Faculty of Dentistry, Department of Orthodontics, Hatay, Turkey \\ ${ }^{b}$ Gaziosmanpaşa University, Faculty of Dentistry, Department of Pediatric Dentistry, Tokat Turkey \\ ${ }^{c}$ Private Dentist, Hatay, Turkey \\ ${ }^{d}$ Mustafa Kemal University, Faculty of Dentistry, Department of Prosthodontics, Hatay, Turkey \\ ${ }^{e}$ Mustafa Kemal University, Faculty of Arts and Sciences, Department of Physics, Atom and Molecular Physical \\ Education Department, Hatay, Turkey
}

\begin{abstract}
The aim of this study was to compare the hardness and elastic modulus of orthodontic adhesives cured with different light-curing units, based on light-emitting diodes. Standardized samples of orthodontic adhesives, Transbond $^{T M}$ XT, Opal ${ }^{\circledR}$ Bond $^{T M}$ and Light Bond ${ }^{T M}$ were prepared in cylinder blocks and cured for three seconds with Valo Ortho LED (Ultradent Products, South Jordan, Utah) and Valo LED High-Power Mode. After grinding and polishing, specimens were stored in distilled water at $37^{\circ} \mathrm{C}$ for one day. Specimens were investigated using nanoindenter. Employment of Valo Ortho unit has resulted in significantly higher elastic modules for Transbond ${ }^{\mathrm{TM}}$ $\mathrm{XT}(p=0.041)$. The highest nanohardness and elastic modules were measured for Transbond ${ }^{\mathrm{TM}} \mathrm{XT}$ cured with Valo Ortho $\left(9.47 \mathrm{GPa} ; 81.85 \mathrm{GPa}\right.$, respectively) and lowest for Opal ${ }^{\circledR}$ Bond $^{\mathrm{TM}}$ for both Valo Ortho (0.44 GPa; $14.52 \mathrm{GPa}$, respectively) and Valo High-Power groups (0.44 GPa; $11.84 \mathrm{GPa}$, respectively).
\end{abstract}

DOI: 10.12693/APhysPolA.132.697

PACS/topics: $62.20 .-\mathrm{x}, 62.20 . \mathrm{Qp}$

\section{Introduction}

Light-cured materials developed for bracket bonding have been frequently preferred in the orthodontic field because of their ease of use, reduced risk of contamination and longer working time [1-3]. Higher surface hardness is a good indicator for the degree of the conversion and desired mechanical property of these materials [4-6]. In case of insufficient polymerization of resins, deterioration of the mechanical properties of cured materials, such as the increase of water sorption and a decrease in the hardness, may occur [7]. Poor polymerization of resin-based materials also adversely affects bond strength [8].

The light source is an important factor for adequate polymerization efficiency [9]. For reduction of curing time, new curing device technologies have been developed [10]. Polymerization by a conventional halogen lights with the 300 to $400 \mathrm{~mW}$ intensity requires curing times of 20 to 40 seconds, to reach adequate bond strengths, per bracket $[11,12]$. Light-emitting diode (LED) technology (at levels up to $1600 \mathrm{~mW}$ ), which is an alternative to the conventional halogen lights, reduces the curing time for bracket bonding [12-14]. Shorter curing times are always preferable to improve clinical outcomes and are especially advantageous for pediatric patients $[6,8]$. Third generation, high-intensity LED curing units, with multiple diodes and dual emission peaks, which are now the newest

*corresponding author; e-mail: fundagulbilgic@hotmail.com technology of light curing for bracket bonding, have been introduced to allow curing time reduction for sufficient polymerization $[8,15]$ Valo LED (Ultradent Products, South Jordan, Utah), which is a third generation LED curing unit, has different curing modes, including standard mode with $1000 \mathrm{~mW} / \mathrm{cm}^{2}$ of light intensity, highpower mode with $1400 \mathrm{~mW} / \mathrm{cm}^{2}$ of light intensity and plasma mode, Valo Ortho with $3200 \mathrm{~mW} / \mathrm{cm}^{2}$ of light intensity.

Application of nano-indentation is a useful method for testing the mechanical properties of many restorative materials and nanomechanical characteristics of low amounts of human enamel surface. This technique is a very powerful method, capable of measuring samples of a very small size, such as nanocomposites, and obtaining reliable results $[16,17]$. The hardness and the elastic modulus of the specimens, which have very small volume, can be calculated mathematically in nanoindentation testing [18].

The nanomechanical properties of the light-cured composite resin (LCR), used in orthodontic bonding, is important for the success of clinical practice. Polymerization performance may change, depending on the material to be cured, as well as the light source [19]. However, there is very limited number of studies available, providing information about influence of third-generation LED LCUs on LCR. The purpose of this in vitro study was to investigate the hardness and elastic modulus of the three different LCRs for bracket bonding, cured with Valo Ortho and Valo High-Power at shortest manufacturer recommended curing times. 


\section{Materials and methods}

No ethical approval was needed for this laboratory study. The presented study examines the performance of Valo Ortho and Valo High-Power curing lights with three different LCR materials. These materials were Transbond $^{\mathrm{TM}}$ XT Light Cure Adhesive (3M Unitek, Monrovia, Calif), Opal ${ }^{\circledR}$ Bond $^{\mathrm{TM}}$ (Ultradent products, USA) and Light Bond $^{T M}$ (Reliance Orthodontic Products, Itasca, Ill) (Table I).

Twenty pcs of polystyrene (PS) and poly(methylmethacrylate) (PMMA) cylinders, $10 \mathrm{~mm}$ thick, $50 \mathrm{~mm}$ in diameter were fabricated. In the center of one of the flat surfaces, of each cylinder block, a cavity, with the depth of $2 \mathrm{~mm}$ and the diameter of $10 \mathrm{~mm}$, was prepared. Margins of the prepared cavity were subjected to cyanoacrylate adhesive treatment. PMMA blocks were randomly divided into two groups of three cylinders. Each cavity was filled with one of the tested LCR materials, according to their group. Each sample was pressed with mylar strip to extrude excess material and make a smooth surface. All specimens were light cured, according to the manufacturers' instructions, for three seconds with one of the selected curing protocols.

TABLE I

Materials employed in present study.

\begin{tabular}{l|l|l}
\hline \hline Material & Manufacturer & Composition \\
\hline Transbond $^{T M}$ & $\begin{array}{l}\text { 3M Unitek, Mon- } \\
\text { rovia, Calif } \\
\text { Ultradent pro- } \\
\text { Opal }\end{array}$ & $\begin{array}{l}\text { Bis-GMA, Bis-EMA, TEGDMA, } \\
\text { silanated quartz, submicron silica } \\
\text { Bond }\end{array}$ \\
Light Bond $^{T M}$ & $\begin{array}{l}\text { Bisphenol A diglycidyl ether di- } \\
\text { methacrylates (Bis-GMA) Ethyl } \\
\text { 4-dimethylaminobenzoate } \\
\text { dontic Products, } \\
\text { Itasca, Ill }\end{array}$ & $\begin{array}{l}\text { Bisphenol A diglycidyl ether di- } \\
\text { methacrylates (Bis-GMA) Triet- } \\
\text { hylene glycol dimethacrylate }\end{array}$
\end{tabular}

Group 1. Prepared cavities were filled with Transbond $^{T M}$ XT, Opal ${ }^{\circledR}$ Bond $^{T M}$ and Light Bond ${ }^{T M}$. Materials were cured with the VALO Ortho LED, $3200 \mathrm{~mW} / \mathrm{cm}^{2}$ for $3 \mathrm{~s}$.

Group 2. Prepared cavities were filled with Transbond $^{T M}$ XT, Opal ${ }^{\circledR}$ Bond $^{T M}$ and Light Bond ${ }^{T M}$. These materials were cured with the VALO LED High-Power, $1400 \mathrm{~mW} / \mathrm{cm}^{2}$ for $3 \mathrm{~s}$.

Specimens were then incubated in distilled water in the light-proof plastic tube at $37^{\circ} \mathrm{C}$ for 1 day. After $24 \mathrm{~h}$, irregularities in the surface were eliminated and parallelism of the material surface and the cylinder surface was ensured by grinding with 1200, 2400 and 4000 grit (SiC) sandpaper for 1 minute, respectively. Later 6, 3 and 1 nano diamond lap wheels were used for polishing.

\subsection{Nano-indentation tests}

In this study, nanomechanical tests of the LCR were performed with Hysitron Triboindenter TI 950 nanoindentation apparatus. Load resolution of this machine was less than $1 \mathrm{nN}$ and displacement resolution was $0.04 \mathrm{~nm}$.
Berkovich diamond indenter tip test was carried out to evaluate the nanohardness and elastic modulus of specimens. The tip was calibrated with a fused quartz reference sample. In order to record the morphological images of the indents, the nanoindenter was also operated in Scanning Probe Mode (SPM). Surface roughness of the samples was measured using SPM. Maximum load was determined as $6000 \mu \mathrm{N}$ under a loading/unloading rate of $1200 \mu \mathrm{N} \mathrm{s}^{-1}$, and the peak load was held for $2 \mathrm{~s}$. For a particular load, at least six indentation tests were conducted on the sample surface, to increase the reliability of the experimental results. Oliver-Pharr [20] method was used to analyse the nanoindentation load-displament curves. In this model contact area and nanohardness are defined as,

$$
H_{\text {nano }}=\frac{P_{\max }}{A}, A_{\mathrm{c}}=24.5 h_{\mathrm{c}}^{2},
$$

where $P_{\max }$ is the maximum test load and $A$ is the projected contact area at $P_{\max }, h$ is depth of penetration of the needle. Elastic modulus $E_{\mathrm{r}}$ was calculated using

$$
E_{\mathrm{r}}=\frac{\sqrt{\pi}}{2} \frac{S}{\sqrt{24.5} h_{c}}
$$

where $S$ is the contact stiffness, computed from the initial slope of the unloading curve at $P_{\max }[32,33]$.

Tn our study, the fore-mentioned computational procedure was used to calculate the nanohardness and elastic modulus of the three different LCR materials, cured with Valo Ortho and Valo High-Power.

Kolmogorov-Smirnov $Z$ test was used for sample distributions. The experimental results were statistically analyzed using one-way analysis of variance (ANOVA) at the level of significance $p<0.05$. Analysis was performed using the SPSS statistical software (Statistical Package for the Social Sciences; SPSS Inc, Chicago, IL, USA).

\section{Results}

Valo Ortho unit resulted in significantly higher elastic modules for Transbond ${ }^{\mathrm{TM}}$ XT $(p=0.041)$ (Table II). Values of hardness and elastic modulus of Transbond ${ }^{\mathrm{TM}} \mathrm{XT}$, Opal ${ }^{\circledR}$ Bond $^{\mathrm{TM}}$ and Light Bond ${ }^{\mathrm{TM}}$, cured with Valo Ortho and Valo High-Power show significant differences from each other $(p<0.05)$. The highest nanohardness and elastic modules were measured for Transbond ${ }^{\mathrm{TM}} \mathrm{XT}$, cured with Valo Ortho (9.47 GPa; $81.85 \mathrm{GPa}$, respectively) and the lowest values were obtained for Opal ${ }^{\circledR}$ Bond ${ }^{\top \mathrm{M}}$ for both, Valo Ortho (0.44 GPa; $14.52 \mathrm{GPa}$, respectively) and Valo High-Power (0.44 GPa; $11.84 \mathrm{GPa}$, respectively) groups (Tables II and III).

Load-indentation depth curves obtained during nanoindentation tests for LCR materials cured with Valo Ortho and Valo High-Power are shown in Fig. 1.

Three different load-depth curves of nanoindentation tests for LCR materials are shown in Fig. 1. The curves demonstrate a smooth shape, and no pop-in could be detected. The Oliver Pharr procedure was used to evaluate the nanohardness and elastic modulus values. 


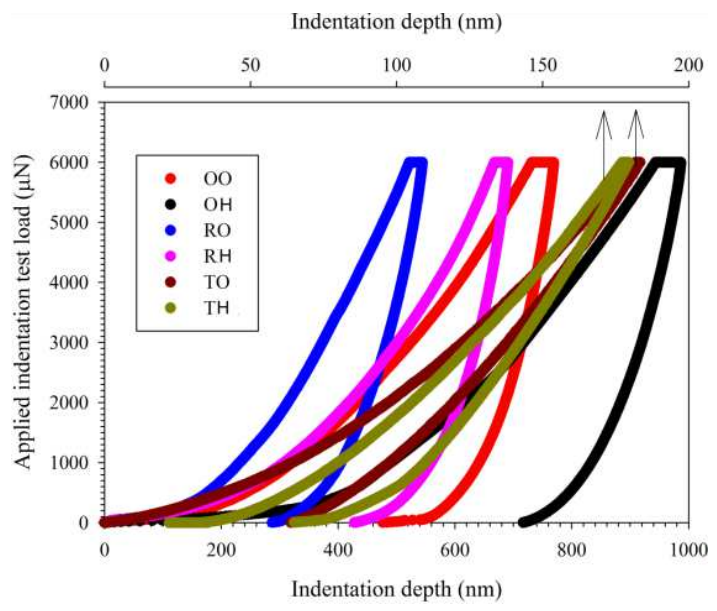

Fig. 1. Results of indentation test. Load versus indentation depth of examined materials. (OO: $\mathrm{Opal}^{\circledR}$ Bond $^{T M}$, cured with Valo Ortho; OH: Opal ${ }^{\circledR}$ Bond $^{T M}$, cured with Valo High-Power; RO: Light Bond ${ }^{\mathrm{TM}}$, cured with Valo Ortho; RH: Light Bond ${ }^{T M}$, cured with Valo HighPower; TO: Transbond ${ }^{\mathrm{TM}} \mathrm{XT}$, cured with Valo Ortho; TH: Transbond ${ }^{\mathrm{TM}} \mathrm{XT}$, cured with Valo High-Power).

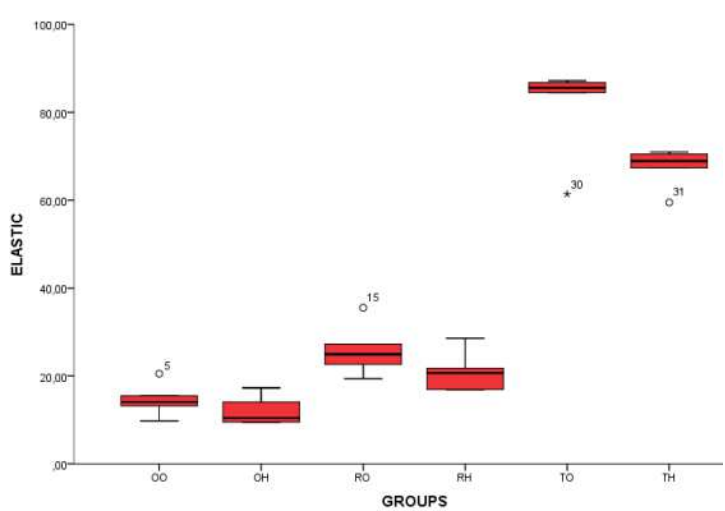

Fig. 2. Levels of elastic modulus (GPa) of each composite, cured by each of the two light-curing units $(p<0.05)$.

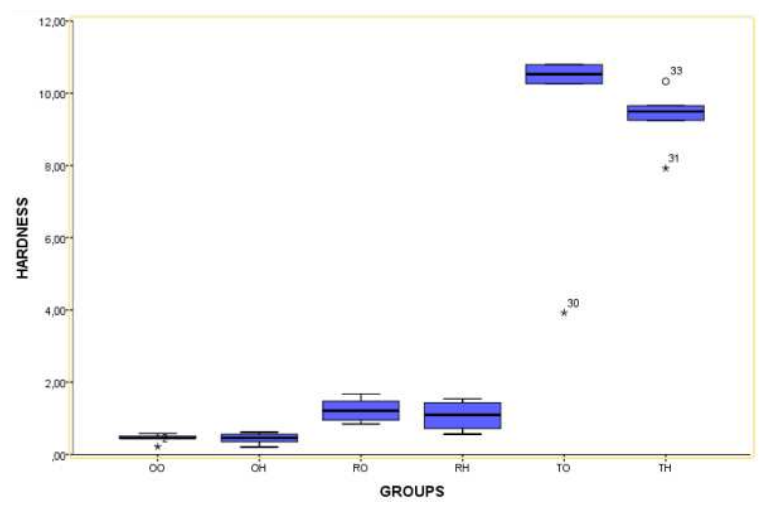

Fig. 3. Levels of hardness (GPa) of each composite, cured by each of the two light-curing units $(p<0.05)$.
TABLE II

Mean values of hardness $(\mathrm{GPa})$ and elastic modulus $(\mathrm{GPa})$ of the all tested composites, cured by each of the two light-curing units $(p<0.05)$.

\begin{tabular}{c|c|c|c}
\hline \hline \multirow{2}{*}{ Materials } & \multicolumn{2}{|c|}{ VALO mode } & \multirow{2}{*}{$p$} \\
\cline { 2 - 3 } & $\begin{array}{c}\text { High-power } \\
\text { Mean SD }\end{array}$ & $\begin{array}{c}\text { Ortho } \\
\text { Mean SD }\end{array}$ & \\
\hline Transbond XT hardness & $9.35 \pm 0.79$ & $9.47 \pm 2.73$ & 0.132 \\
Opal Bond hardness & $0.44 \pm 0.15$ & $0.44 \pm 0.12$ & 1000 \\
Light Bond hardness & $1.07 \pm 0.40$ & $1.22 \pm 0.34$ & 0.394 \\
Transbond XT elast. modul. & $67.69 \pm 4.24$ & $81.85 \pm 10.08$ & $0.041^{*}$ \\
Opal Bond elastic modulus & $11.84 \pm 3.16$ & $14.52 \pm 3.5$ & 0.24 \\
Light Bond elastic modulus & $20.91 \pm 4.28$ & $25.77 \pm 5.46$ & 0.132
\end{tabular}

TABLE III

Hardness and elastic modulus values of Transbond ${ }^{\mathrm{TM}} \mathrm{XT}$ (T), Opal ${ }^{\circledR}$ Bond $^{\mathrm{TM}}(\mathrm{O})$ and Light Bond ${ }^{\mathrm{TM}}(\mathrm{R})$, cured with Valo Ortho and Valo High-Power groups $(p<0.05)$.

\begin{tabular}{c|c|c|c|c|c|c}
\hline \hline & \multicolumn{3}{|c|}{ Mean rank } & \multicolumn{3}{c}{ P value } \\
\hline & $\mathrm{T}$ & $\mathrm{O}$ & $\mathrm{R}$ & $\mathrm{T} \& \mathrm{O}$ & $\mathrm{T} \& \mathrm{R}$ & $\mathrm{O} \& \mathrm{R}$ \\
\hline \multicolumn{7}{c}{ VALO Ortho } \\
\hline Hardness & 9.47 & 0.44 & 1.22 & $* * *$ & $* * *$ & $* * *$ \\
Elastic modules & 81.85 & 14.52 & 25.77 & $* * *$ & $* * *$ & $* * *$ \\
\hline \multicolumn{8}{c}{ Valo High-power } \\
\hline Hardness & 9.35 & 0.44 & 1.07 & $* * *$ & $* * *$ & $* * *$ \\
Elastic modules & 67.69 & 11.84 & 20.91 & $* * *$ & $* * *$ & $* * *$
\end{tabular}

\section{Discussion}

The biological, chemical, mechanical and physical properties of the light-cured orthodontic bonding adhesives are important for the success of treatment. Mechanical properties and adhesive polymerization levels of lightcured adhesives may change, depending on light intensity of the devices. Previous studies reported that there was a significant dependence between hardness characteristics of orthodontic composites and the type of curing unit $[10,21]$

The present in vitro study evaluated the effects of the two different curing units on the mechanical properties (hardness and elastic modulus) of the light-cured adhesives by means of nanoindentation analysis. Analysis region of each adhesive group and type of indenter may change the values of mechanical properties of materials [22]. The analysis of nanoscale mechanical properties, such as hardness, modulus of elasticity, fracture toughness, yield strength of the adhesives, can be made based on the nanoindentation test [23, 24]. Nanoindentation test is a very powerful method to measure samples of smaller sizes, with reliable values of mechanical properties, as the applied force is at micro and nano level $[25,26]$. In our study, nanoindentation test procedures were performed immediately after the specimens were stored in distilled water for 24 hours to provide convenient storage conditions, due to fact that dehydration increases the hardness and modulus of elasticity, and the fragility of the samples [27, 28]. 
Study was conducted with a VALO ORTHO curing unit with a light intensity of $3200 \mathrm{~mW}$ per square centimeter and an exposure time of $3 \mathrm{~s}$, and with VALO LED high-power mode with a light intensity of $1400 \mathrm{~mW}$ and an exposure time of $3 \mathrm{~s}$. In our study, as a result of the comparison of the light-cured orthodontic bonding adhesives with each other, it was detected that Transbond XT, Opal Bond and Light Bond had different hardness and elastic modulus values. Among all samples, Transbond XT, cured with VALO ORTHO, had the highest hardness and elastic modulus values (9.47 GPa; 81.85 GPa, respectively). Opal Bond cured with VALO LED high-power had the lowest hardness and elastic modulus values (0.44 GPa; $11.84 \mathrm{GPa}$, respectively).

Uysal et al. [21] evaluated the microhardness of three orthodontic adhesives (Kurasper F, Light-Bond, Transbond XT) cured with light and high intensity quartz tungsten halogen. They found that the highest overall hardness value had Light-Bond specimens. It was reported that due to lower degree of conversion, chemically cured composites had smaller hardness values than the light-cured ones [24, 29].

In another study, related to light-cured lingual retainer adhesives, Light Cure Retainer (Reliance) showed a higher degree of hardness change than Transbond Lingual Retainer (3MUnitek) [1]. These results might be due to different test systems and storage conditions used.

Materials with higher values of surface hardness might be preferable for the clinician and for the patient [25]. Shorter curing times, obtained with high-light-intensity LED dental curing units, can provide sufficient polymerization and depth of cure for LCR [15]. According to many researchers, hardness, and strength of the adhesives increases with higher light intensity [30]. Timesaving procedures with LED units reduce chair time during bracket bonding and also the bracket failure rates [10]. Reduction of irradiation time has not caused adverse effects to mechanical properties of materials [3133]. Recent studies had highlighted that the Valo LCU in high-power mode $\left(1400 \mathrm{~mW} / \mathrm{cm}^{2}\right.$ for $\left.12 \mathrm{~s}\right)$ and in standard mode and the Elipar LCU produced similar microhardness values, on the surfaces of materials. However using the Valo LCU in extra mode $\left(3200 \mathrm{~mW} / \mathrm{cm}^{2}\right.$ for $6 \mathrm{~s})$ resulted in the lowest microhardness values on the top and bottom surfaces of the tested materials [8]. Leprince et al. stated that irradiation time was not the most important factor in adhesive polymerization, however it is important to achieve polymerization at greater depths [31]. In our study, adhesives cured with VALO ORTHO had higher hardness and elastic modulus values than those cured with VALO LED high-power.

\section{Conclusions}

- When two different curing units are compared, only statistically significant differences are found for the elastic modules for the Transbond XT, which were significantly higher in Valo Ortho group than in Valo High-Power group.
- As a result of the comparison of the three different light-cured orthodontic bonding adhesives, in terms of surface hardness and elastic modulus, we found that Transbond XT cured with Valo Ortho had the highest hardness and elastic module values among studied adhesives.

\section{References}

[1] S. Üşümez, T. Büyükyılmaz, A.I. Karaman, Am. J. Ortodont. Dentofacial Orthoped. 123, 641 (2003).

[2] M. Sfondrini, V. Cacciafesta, C. Klersy, Am. J. Ortodont. Dentofacial Orthoped. 125, 342 (2004).

[3] M.F. Sfondrini, V. Cacciafesta, A. Pistorio, G. Sfondrini, Am. J. Ortodont. Dentofacial Orthoped. 119, 30 (2001).

[4] S.I. Ramoglu, S. Usumez, T. Buyukyilmaz, Angle Orthodont. 78, 140 (2008).

[5] K. Okada, S. Tosaki, K. Hirota, W. Hume, Dental Mater. 17, 34 (2001).

[6] B. Kitchens, M. Wells, D. Tantbirojn, A. Versluis, Int. J. Paediatric Dentistry 25, 79 (2015).

[7] N. Silikas, G. Eliades, D. Watts, Dental Mater. 16, 292 (2000).

[8] N. Gonulol, S. Ozer, E.S. Tunc, Int. J. Paediatric Dentistry 26, 376 (2016).

[9] A. Santini, Dental Update 37, 214 (2010).

[10] A.A. Oz, A.Z. Oz, S. Arici, Am. J. Ortodont. Dentofacial Orthoped. 149, 212 (2016).

[11] M.F. Sfondrini, V. Cacciafesta, A. Scribante, C. Klersy, Am. J. Ortodont. Dentofacial Orthoped. 125, 342 (2004).

[12] P.S. Fleming, T. Eliades, C. Katsaros, N. Pandis, Am. J. Ortodont. Dentofacial Orthoped. 143, S92 (2013).

[13] W.J. Dunn, L.J. Taloumis, Am. J. Ortodont. Dentofacial Orthoped. 122, 236 (2002).

[14] D.L. Leonard, D.G. Charlton, H.W. Roberts, M.E. Cohen, J. Esthetic Restorative Dent. 14, 286 (2002).

[15] J.D. Ward, B.J. Wolf, L.P. Leite, J. Zhou, Angle Orthodont. 85, 1064 (2015).

[16] M. Shokrieh, M. Hosseinkhani, M. Naimi-Jamal, H. Tourani, Polymer Test. 32, 45 (2013).

[17] S.H. Raji, H. Banimostafaee, F. Hajizadeh, Dental Res. J. 11, 67 (2014).

[18] M. Iijima, T. Muguruma, W.A. Brantley, T. Yuasa, J. Uechi, I. Mizoguchi, Am. J. Ortodont. Dentofacial Orthoped. 138, 420 (2010).

[19] K. Ikemura, T. Endo, Dental Mater. J. 29, 481 (2010).

[20] W.C. Oliver, G.M. Pharr, J. Mater. Res. 7, 1564 (1992).

[21] T. Uysal, F.A. Basciftci, Y. Sener, M.S. Botsali, A. Demir, Angle Orthodont. 78, 134 (2008).

[22] N. Kohda, M. Iijima, W. Brantley, T. Muguruma, T. Yuasa, S. Nakagaki, I. Mizoguchi, Angle Orthodont. 82, 187 (2012). 
[23] G. Marshall, M. Balooch, R. Gallagher, S. Gansky, S. Marshall, J. Biomed. Mater. Res. 54, 87 (2001).

[24] H. Altan, F. Bilgic, Z. Arslanoglu, E. Kale, A.K. Kale, A. Altan, O. Sahin, Acta Phys. Pol. A 130, 394 (2016).

[25] J. Zhou, L.L. Hsiung, J. Biomed. Mater. Res. Part A 81, 66 (2007).

[26] C. Bréchignac, P. Houdy, M. Lahmani, Nanomaterials and Nanochemistry, Springer, Berlin Heidelberg 2008.

[27] L. Zheng, J. Zheng, L. Weng, L. Qian, Z. Zhou, Wear 271, 2297 (2011).

[28] F. Lippert, D.M. Parker, K.D. Jandt, J. Colloid Interface Sci. 280, 442 (2004).
[29] K.A. Schulze, S.J. Marshall, S.A. Gansky, G.W. Marshall, Dental Mater. 19, 612 (2003).

[30] J. Ferracane, J. Mitchem, J. Condon, R. Todd, J. Dental Res. 76, 1508 (1997).

[31] J. Leprince, J. Devaux, T. Mullier, J. Vreven, G. Leloup, Operative Dentist. 35, 220 (2010).

[32] U.B. Campregher, S. Samuel, C. Fortes, A. Medina, F.M. Collares, F.A. Ogliari, J. Contemp. Dent. Pract. 8, 35 (2007).

[33] F.A. Rueggeberg, Dental Mater. 27, 39 (2011). 